\title{
Letter to the Editor Concerning "Glycosylated Hemoglobin as a Surrogate for the Prediction of Cardiovascular Events in Cardiovascular Outcome Trials Comparing New Antidiabetic Drugs to Placebo"
}

\author{
Saeed Shoar ${ }^{a}$ Mohammad Naderan ${ }^{b}$ Nasrin Shoar ${ }^{c}$ Venkat R. Modukuru ${ }^{d}$ \\ a Department of Clinical Research, ScientificWriting Corporation, Houston, TX, USA; ${ }^{b}$ Faculty of Medicine, \\ Tehran University of Medical Sciences, Tehran, Iran; ' Faculty of Medicine, Kashan University of Medical Sciences, \\ Kashan, Iran; d Department of Surgery, Metropolitan Hospital Center, New York Medical College, Manhattan, NY, \\ USA
}

\section{Dear Editor,}

As an indicator of long-term glycemic control in patients with diabetes mellitus (DM), glycosylated hemoglobin $\left(\mathrm{HbA}_{1 \mathrm{c}}\right)$ has proved to be superior over fasting blood sugar as a reliable and a more accurate measure of diabetes treatment [1]. Although the clinical implications of $\mathrm{HbA}_{1 \mathrm{c}}$ have been highlighted by widely cited guidelines in relation to the microvascular complications of DM [2], the role of $\mathrm{HbA}_{1 \mathrm{c}}$ in predicting cardiovascular $(\mathrm{CV})$ outcome is being cumulatively investigated [3].

An increasing body of knowledge supports the independent and linear association of $\mathrm{HbA}_{1 \mathrm{c}}$ level and the severity of atherosclerotic peripheral arterial disease $(\mathrm{PAD})$ $[4,5]$, the literature has taken the prognostic value of $\mathrm{HbA}_{1 \mathrm{c}}$ to the next level, i.e., predicting the incidence of macrovascular diseases in nondiabetic individuals $[3,5,6]$.

The timely publication of the paper by Ambrosi et al. [7] in a recent issue of Cardiology highlights a valuable standpoint for clinical trials of antidiabetic drugs to consider $\mathrm{HbA}_{1 \mathrm{c}}$ as a predictive measure for the CV benefits of the new medications being tested. As this meta-analysis concludes, mean decrease in $\mathrm{HbA}_{1 \mathrm{c}}$ is directly correlated with a reduction in major $\mathrm{CV}$ events. Furthermore, such a relationship is independent of the weight loss observed during the study period of the included clinical trials. We sought to provide a few perspectives from which this research study could be interpreted more practically.

This meta-analysis could have drawn a clearer picture of the history of DM-related CV complications at the baseline for each of the included clinical trials. While there might have been a lack of information at the individual level, the frequency of $\mathrm{CV}$ disease of any type at the time of enrollment has been depicted for each trial and it ranged from 41 to $100 \%$ of the patients. If provided, the relationship between post-treatment $\mathrm{HbA}_{1 \mathrm{c}}$ alteration and the de novo incidence of CV complications of DM would be much clearer.

Although the change in $\mathrm{HbA}_{1 \mathrm{c}}$ was correlated with the change in $\mathrm{CV}$ events at the end of the follow-up period, the duration of follow-up was not highlighted in the meta-analysis. Previous studies have shown the clinical utility of $\mathrm{HbA}_{1 \mathrm{c}}$ as a predictor of short-term mortality after acute coronary syndrome, and it also bears prognostic value for long-term CV complications of lesser severity. In either case, more elaboration on the follow-up period karger@karger.com www.karger.com/crd

(c) 2020 S. Karger AG, Basel

Karger"
Saeed Shoar, MD

Department of Clinical Research, ScientificWriting Corporation 6345 Garth Rd., St\#110, P.B.\#109 Baytown, TX 77521 (USA)

saeedshoar@scientificwriting.org 
during which the incidence of $\mathrm{CV}$ events was measured against the net change in $\mathrm{HbA}_{1 \mathrm{c}}$ would have expanded our concept of its time-sensitive predictive value.

Interestingly, the relative change in the major $\mathrm{CV}$ events between the new antidiabetic drug and placebo ranged from -3 to $26 \%$ compared to the unidirectional change in $\mathrm{HbA}_{1 c}$ percentage. A sensitivity analysis excluding these outliers would shed a brighter light on the relationship between $\mathrm{HbA}_{1 \mathrm{c}}$ and $\mathrm{CV}$ events.

The meta-analysis by Ambrosi et al. [7] truly highlights the easing role of a universally accepted marker as a surrogate for the prediction of CV outcomes in clinical trials of antidiabetic drugs. However, the above-men- tioned points can widen our perspectives from which this clinical surrogate is viewed by investigators of future research studies.

\section{Disclosure Statement}

The authors have no conflicts of interest to declare.

\section{Author Contributions}

All authors contributed to the conception of this manuscript, its preparation, and intellectual approval of the final draft.

\section{References}

1 Goldstein DE, Little RR, Lorenz RA, Malone JI, Nathan DM, Peterson CM; American Diabetes Association. Tests of glycemia in diabetes. Diabetes Care. 2003 Jan;26 Suppl 1:S1068.

2 Selvin E, Marinopoulos S, Berkenblit G, Rami T, Brancati FL, Powe NR, et al. Meta-analysis: glycosylated hemoglobin and cardiovascular disease in diabetes mellitus. Ann Intern Med. 2004 Sep;141(6):421-31.

3 Mitsios JP, Ekinci EI, Mitsios GP, Churilov L, Thijs V. Relationship between Glycated Hemoglobin and Stroke Risk: A Systematic Review and Meta-Analysis. J Am Heart Assoc. 2018 May;7(11):e007858.
4 Selvin E, Wattanakit K, Steffes MW, Coresh J, Sharrett AR. HbAlc and peripheral arterial disease in diabetes: the Atherosclerosis Risk in Communities study. Diabetes Care. 2006 Apr; 29(4):877-82.

5 Haring R, Baumeister SE, Lieb W, von Sarnowski B, Völzke H, Felix SB, et al. Glycated hemoglobin as a marker of subclinical atherosclerosis and cardiac remodeling among nondiabetic adults from the general population. Diabetes Res Clin Pract. 2014 Sep;105(3): 416-23.
6 Pan W, Lu H, Lian B, Liao P, Guo L, Zhang M. Prognostic value of $\mathrm{HbAlc}$ for in-hospital and short-term mortality in patients with acute coronary syndrome: a systematic review and meta-analysis. Cardiovasc Diabetol. 2019 Dec;18(1):169.

7 Ambrosi P, Daumas A, Villani P, Giorgi R. Glycosylated Hemoglobin as a Surrogate for the Prevention of Cardiovascular Events in Cardiovascular Outcome Trials Comparing New Antidiabetic Drugs to Placebo. Cardiology. 2020. DOI: 10.1159/000506004. 